\title{
SUPERVISÃO PEDAGÓGICA INTERPARES COM VISTA AO DESENVOLVIMENTO PESSOAL E PROFISSIONAL DE PROFESSORES: UM ESTUDO EXPLORATÓRIO
}

\author{
José CASTILHO ${ }^{1}$ \\ César Meira SÁ ${ }^{2}$
}

RESUMO: Este artigo apresenta um estudo durante o qual se desenvolveu um processo de supervisão pedagógica interpares como forma de contribuir para o desenvolvimento pessoal e profissional dos professores envolvidos e melhorar a qualidade das aprendizagens dos seus alunos. Tratou-se de um processo de investigação-ação, com recurso a ciclos de observação mútua de aulas dos professores participantes e a consequente reflexão colaborativa. Foram testadas teorias que defendem a ação pedagógica nas perspectivas interativa, ecológica e desenvolvimental - em que o ensinar não é exclusivo do professor, nem o aprender é exclusivo do aluno. Trata-se antes de um processo de transformação que visa a autonomia de professores e alunos, através da reflexão, da aquisição sistemática de novos conhecimentos, da inovação (experimentação e avaliação de novos métodos, recursos e formas de comunicação), tendo como finalidade a inovação educativa, a melhoria da escola e a transformação da sociedade.

PALAVRAS-CHAVE: Supervisão pedagógica interpares, Trabalho colaborativo entre professores. Desenvolvimento profissional e pessoal do professor. Investigação-ação.

\section{Introdução}

A supervisão pedagógica deixou de ser uma ação exclusivamente exercida em contexto de formação inicial de professores e alargou-se ao âmbito do desenvolvimento pessoal e profissional dos professores, contribuindo para reforçar e melhorar as práticas de ensino e, consequentemente, para melhorar a aprendizagem dos alunos. Esta perspetiva pressupõe que o professor seja um profissional em formação permanente, que a escola seja encarada como uma Comunidade de Aprendizagem e que a Supervisão Pedagógica seja entendida como um processo dialógico e reflexivo de monitorização, acompanhamento e desenvolvimento da prática pedagógica.

\footnotetext{
${ }^{1}$ Professor no Agrupamento de Escolas de Terras de Bouro. Terras de Bouro - Cávado - Portugal. 4840100 - cesarsa@ese.ipvc.pt.

${ }^{2}$ Doutor em Ciências da Educação. FMH - Faculdade de Motricidade Humana. Professor Adjunto. ESE Escola Superior de Educação. Instituto Politécnico de Viana do Castelo. Viana do Castelo - Portugal. 4901-908 - cesarsa@ese.ipvc.pt.
} 
O professor não conduz apenas um processo de ensino virado para a aprendizagem dos seus alunos. Pelo contrário, participa num processo de ensino e aprendizagem em que ele próprio aprende. A aprendizagem é um processo contínuo ao longo da vida visando a adaptação profissional aos novos contextos e dando resposta às transformações sociais (BINDÉ, 2007) e, dessa forma, o professor emerge como um elemento de uma vasta Comunidade de Aprendizagem, que é a Escola. O trabalho com equipas de docentes, permitindo-lhes fixar objetivos em comum, preparar juntos uma ação pedagógica e orientá-la em conjunto, com a observação recíproca das intervenções e discussões, é adequado para fazer evoluir as atitudes e os comportamentos pedagógicos.

Uma metodologia do tipo investigação-ação adequa-se a este processo (COUTINHO et al., 2009), uma vez que as suas práticas investigatórias e científicas permitem analisar o processo em evolução, identificar as transformações que se vão operando e produzir conhecimento emancipatório (MOREIRA, 2001). A observação direta permite identificar os sinais fundamentais do funcionamento da relação pedagógica e, seguindo um processo experimental, assinalar as suas variáveis e examinar as ligações entre elas. Trata-se de uma metodologia eficaz para o desenvolvimento pessoal e profissional dos professores, fazendo aproximar os objetivos individuais (dos docentes) dos objetivos institucionais (Projeto Educativo), através do esforço colaborativo numa espiral de ciclos de reflexão, planificação e ação (COUTINHO et al., 2009).

\section{Supervisão pedagógica e desenvolvimento pessoal e profissional do professor}

A supervisão, quando orientada por uma visão crítica da pedagogia, torna a ação mais consciente, deliberada e suscetível à mudança, contribuindo para a formulação de soluções técnicas e universais para os problemas que se colocam (SCHÖN, 2000). Vieira (2009) defende a Supervisão Pedagógica como teoria e prática de regulação de processos de ensino e aprendizagem em contexto educativo formal e realça o seu carácter indissociável da Pedagogia, que resulta em "[...] thoughful action: action full of thought and thought full of action" (VAN MANEN, 1990 apud VIEIRA, 2009, p.200). A Pedagogia é simultaneamente o objeto e o objetivo da Supervisão em educação, como forma de indagar e melhorar a qualidade do ensino e da aprendizagem e, na perspectiva de Moreira (2010) implica uma postura indagatória e problematizadora visando tanto os 
professores como os alunos sobre quem incide a sua ação, considerando os contextos onde os mesmos se desenvolvem.

O conceito de Supervisão Pedagógica ultrapassou as fronteiras da formação inicial e estende-se atualmente ao âmbito do desenvolvimento profissional do professor, abrangendo os processos de apoio e regulação do ensino e da aprendizagem, a reflexão e investigação sobre a ação educativa e a mudança, e a melhoria das práticas pedagógico-didáticas (ALARCÃO, 2010a; DAY, 1999, 2001, 2004; DAY et al., 2007; VIEIRA; MOREIRA, 2011; ZEPEDA, 2007, 2008). Desta forma, liga-se ao processo de aprendizagem e à melhoria das práticas num contexto de aprendizagem ao longo da vida, contribuindo para o crescimento pessoal e profissional do professor, para a aquisição e reciclagem de conhecimentos de carácter teórico-prático e para a melhoria da qualidade na educação.

Esta linha de pensamento vem na senda da que foi defendida por Day (2001), acerca do desenvolvimento profissional contínuo dos professores para dar resposta aos desafios e constrangimentos que afetam a sua capacidade de se manter motivado e envolvido na ação. Abrange tanto o conjunto das experiências de aprendizagem natural como o conjunto das atividades conscientes e planeadas (formais) com benefício direto ou indireto ao nível individual, do grupo ou da escola, e que contribuem para a melhoria da qualidade da educação na sala de aula. Constitui um processo pelo qual, sozinho ou em colaboração, os professores revêem, renovam e alargam o seu compromisso na qualidade de agentes de mudança visando a finalidade moral do ensino; e pela qual adquirem e desenvolvem criticamente o seu conhecimento, competências técnicas e inteligência emocional, essenciais para conduzir a reflexão no contexto profissional, o planeamento e a prática com os alunos e os colegas. A importância dos pares no desenvolvimento profissional dos professores é reconhecida por Zepeda (2008), para quem as escolas que evoluem como comunidades de aprendizagem criam uma ética de preocupação pela aprendizagem individual e coletiva. A colaboração é, pois, a estratégia de ação que suporta e sustenta uma comunidade de aprendizagem ou, na perspetiva de Alarcão (2010b), uma necessidade que deriva da complexidade das situações da vida atual, com vista ao desenvolvimento, transformação e inovação.

\section{Apresentação do estudo}


Este estudo foi desenvolvido numa escola do norte de Portugal e envolveu o próprio investigador - doravante identificado como PI - e uma colega - doravante identificada como PP - ambos professores da disciplina de Inglês como língua estrangeira. Envolveu ainda duas turmas, uma do oitavo e outra do nono ano de escolaridade, da lecionação de cada um dos professores. Procurou-se dar resposta ao seguinte problema: As práticas colaborativas entre professores num ambiente de supervisão horizontal reflexivo podem contribuir para melhorar o desempenho profissional e pessoal do professor e, consequentemente, contribuir para melhorar o sucesso educativo dos seus alunos?

Neste contexto, emergiram as seguintes questões:

1. Pode um processo de supervisão pedagógica interpares contribuir para reformular a abordagem metodológica e estratégica no processo de ensinoaprendizagem em contexto de sala de aulas?

2. Podem ser identificadas transformações ao nível do desempenho profissional e pessoal dos professores envolvidos num processo de supervisão pedagógica interpares?

3. Que perceção têm os alunos acerca das transformações que se operam ao nível do desempenho profissional e pessoal do seu professor, envolvido num processo de supervisão pedagógica interpares?

4. Podem ser identificadas transformações ao nível do contexto de aprendizagem dos alunos em consequência das transformações operadas ao nível do desempenho profissional e pessoal do professor envolvido num processo de supervisão pedagógica interpares?

Tratou-se de um estudo de natureza qualitativa, em que o design adotado foi a investigação-ação, por ser aquele que melhor se adequa às características do processo de supervisão pedagógica interpares, com recurso a ciclos de observação de aulas e ao trabalho e reflexão colaborativos entre colegas. Seguiu-se preferencialmente a abordagem colaborativa da investigação-ação, ainda que pontualmente ocorressem momentos de abordagem diretiva informal (GLICKMAN et al., 2010). Recorreu-se aos seguintes instrumentos de recolha de dados:

i) seis ciclos de observação de aulas (cada professor-participante foi observado em três ciclos, e observador noutros três);

ii) registo colaborativo de cada uma das aulas observadas, através da descrição naturalista e dando espaço ao confronto escrito entre os pontos de vista do observador e do observado;

iii) sete sessões com dois grupos focalizados de alunos; 
iv) reflexões escritas pelo professor investigador, pela professora participante e pelos alunos.

As aulas observadas constituíram o instrumento privilegiado de recolha de dados, pois observação de aulas e investigação-ação encontram-se intrinsecamente ligados (MOREIRA, 2001). Seguindo o modelo de Glickman (GLICKMAN et al., 2010), estabeleceram-se cinco fases para cada um dos ciclos de observação: as reuniões/encontros de pré-observação; a aula observada e o preenchimento da grelha de observação; a reflexão interativa sobre a aula e o preenchimento de um registo colaborativo da aula observada; a reunião/encontro pós-observação; a reflexão crítica sobre o ciclo.

Tabela 1 - Planificação dos ciclos de observação de aulas

\begin{tabular}{|c|c|c|c|c|}
\hline $\begin{array}{l}\text { Ciclos de } \\
\text { observação } \\
\text { de aulas }\end{array}$ & $\begin{array}{l}\text { Data da } \\
\text { aula } \\
\text { observada }\end{array}$ & Observador & Observado & Focos principais da observação \\
\hline $1^{o}$ ciclo & 30 nov. & $\mathrm{PP}$ & PI & $\begin{array}{l}\text { Encontrar evidências que confirmem ou } \\
\text { desmintam os problemas antecipados }\end{array}$ \\
\hline $2^{\circ}$ ciclo & 09 Dez. & PI & PP & $\begin{array}{l}\text { Encontrar evidências que confirmem ou } \\
\text { desmintam os problemas antecipados }\end{array}$ \\
\hline \multirow[t]{3}{*}{$3^{\circ}$ ciclo } & 11 jan. & $\mathrm{PP}$ & PI & Relação professor-aluno; \\
\hline & & & & Comunicação pedagógica \\
\hline & & & & Gestão das relações interpessoais \\
\hline \multirow[t]{2}{*}{$4^{\circ}$ ciclo } & 20 jan. & PI & PP & O processo de ensino-aprendizagem: \\
\hline & & & & $\begin{array}{l}\text { Atividades, gestão do tempo, } \\
\text { participação/interesse dos alunos }\end{array}$ \\
\hline \multirow[t]{2}{*}{$5^{\circ}$ ciclo } & 25 jan. & PP & PI & O processo de ensino-aprendizagem: \\
\hline & & & & $\begin{array}{l}\text { Atividades, gestão do tempo, } \\
\text { participação/interesse dos alunos }\end{array}$ \\
\hline \multirow[t]{2}{*}{$6^{\circ}$ ciclo } & 02 fev. & PI & $\mathrm{PP}$ & Comportamento dos alunos; \\
\hline & & & & $\begin{array}{l}\text { Gestão da comunicação pedagógica por } \\
\text { parte da professora }\end{array}$ \\
\hline
\end{tabular}

Fonte: Elaborada pelos autores.

As sessões com os grupos focalizados de alunos ocorreram de janeiro a março as primeiras sessões realizaram-se quando ainda decorriam os ciclos de observação de aulas; as últimas sessões realizaram-se após o termo dos ciclos de observação de aulas. Foram conduzidas como conversas em que o investigador, no papel de moderador, 
procurou gerir os tempos, introduzindo os temas para reflexão - tratando-se de um guião (Tabela 2), constituiu uma orientação dos temas a abordar sem se tratar de um questionário estruturado, nem mesmo semiestruturado. $\mathrm{O}$ moderador assumiu o papel de agente facilitador do grupo e teve como uma das suas tarefas fundamentais de apresentar aos membros do grupo explicações claras e objetivas sobre o trabalho a ser desenvolvido. Todas as sessões foram gravadas e posteriormente transcritas, antes de serem analisadas.

A opção pela constituição de dois grupos focalizados de alunos enquanto instrumento de recolha de dados apresentou vantagens específicas para este estudo pois permitiu investigar as complexidades e as experiências individuais dos alunos das duas turmas de modo a aprofundar os dados recolhidos através de outros instrumentos, confrontar as percepções dos professores com as percepções dos alunos, indagar de que forma uns e outros podem promover a transformação mútua e, finalmente, a triangulação de dados. Houve algum cuidado com a seleção dos participantes: foram organizados dois grupos, representativos de cada uma das turmas participantes no estudo, de cinco alunos cada, obedecendo ao seguinte critério único: os alunos são representativos dos níveis de proficiência da língua inglesa, esperados para o seu nível de aprendizagem.

Tabela 2 - Planificação das sessões dos grupos focalizados

\begin{tabular}{|c|c|c|c|}
\hline $\begin{array}{l}\text { Sessões com os } \\
\text { grupos focais }\end{array}$ & $\begin{array}{c}\text { Grupo } 1 \\
\left(9^{\circ} \text { ano }\right)\end{array}$ & $\begin{array}{c}\text { Grupo } 2 \\
\left(8^{\circ} \text { ano }\right)\end{array}$ & Temas \\
\hline $1^{\mathrm{a}}$ & $\mathrm{X}$ & & $\begin{array}{l}\text { Como os alunos vêm a Língua Inglesa no contexto da sua } \\
\text { aprendizagem escolar. }\end{array}$ \\
\hline $2^{\mathrm{a}}$ & & $\mathrm{X}$ & $\begin{array}{l}\text { Como os alunos vêm a Língua Inglesa no contexto da sua } \\
\text { aprendizagem escolar }\end{array}$ \\
\hline $3^{\mathrm{a}}$ & $\mathrm{X}$ & & $\begin{array}{l}\text { As atividades desenvolvidas durante as aulas de Inglês e o } \\
\text { seu objetivo de aprendizagem }\end{array}$ \\
\hline \multirow{2}{*}{$4^{\mathrm{a}}$} & \multirow{2}{*}{$\mathrm{X}$} & & O papel do professor e o papel do aluno \\
\hline & & & A comunicação pedagógica \\
\hline \multirow{3}{*}{$5^{\mathrm{a}}$} & & \multirow{3}{*}{$\mathrm{X}$} & $\begin{array}{l}\text { As atividades desenvolvidas durante as aulas de Inglês e o } \\
\text { seu objetivo de aprendizagem }\end{array}$ \\
\hline & & & O papel do professor e o papel do aluno \\
\hline & & & A comunicação pedagógica \\
\hline
\end{tabular}

Fonte: Elaborada pelos autores. 
Todos os documentos recolhidos durante o estudo foram analisados, utilizandose para o efeito a técnica de análise de conteúdo, que por via indutiva resultou em categorias e subcategorias de análise, em consequência da primeira e das leituras subsequentes, a primeira mais superficial e as seguintes mais aprofundadas (tendo em conta as unidades de sentido e o significado das palavras). A pertinência e validade das categorias e subcategorias foram sendo asseguradas ao longo das leituras posteriores, mais aprofundadas e viradas para o conteúdo e a semântica, correspondendo à fase da codificação documental. Foi usada a seguinte técnica de codificação: primeiro foram analisados linha a linha os registos colaborativos das aulas observadas, as reflexões individuais dos professores participantes, as transcrições das sessões com os grupos focalizados de alunos ou as reflexões individuais dos alunos, procedendo-se ao registo de notas; posteriormente, estas notas foram agrupadas numa matriz de frequência ou ocorrência. Para o efeito foram usadas cores diferentes, que permitiram encontrar pontos em comum e estabelecer padrões de regularidade, com os quais se estabeleceram categorias e subcategorias de análise.

\section{Apresentação e discussão dos dados}

Estabeleceram-se quatro categorias de análise para os registos colaborativos das aulas observadas (ver Tabela 3). A primeira categoria, "descrição de ocorrências", centrou-se essencialmente nas entradas dos observadores, procurando-se constantes descritivas da realidade observada na sala de aulas, as quais vieram a constituir-se como sete subcategorias. Constatou-se que todas as entradas dos dois observadores focaram os comportamentos (tanto do professor como do aluno), a forma como o professor conduziu o processo de ensino e a forma como o aluno participou nesse processo. Constatou-se ainda que ambos os professores participantes, na qualidade de observadores, focaram mais a sua atenção no desempenho do professor do que no desempenho dos alunos, o que é demonstrado pela ausência em algumas das aulas observadas de registos relacionados com demonstrações de iniciativa/autonomia por parte dos alunos e de interações professor-aluno/alunos.

A segunda categoria, "interpretações do observador", centrou-se nos comentários/inferências do observador(a) e permitiu encontrar seis constantes, ou subcategorias. Verificou-se que os comentários focaram com mais incidência o 
ambiente de aprendizagem (a atitude de aprendizagem dos alunos e a forma como o professor geriu os conflitos/comportamentos) e as atividades e estratégias desenvolvidas durante as aulas observadas. A gestão do tempo, dos recursos/materiais e da comunicação pedagógica foram aspetos menos focados.

Tabela 3 - Grelha de codificação das categorias e subcategorias de análise dos registos colaborativos das aulas observadas

\begin{tabular}{|c|c|c|c|c|c|c|c|}
\hline \multirow[b]{2}{*}{ Categorias: } & \multirow[b]{2}{*}{ Subcategorias: } & \multicolumn{3}{|c|}{$\begin{array}{l}\text { Aulas em } \\
\text { que PI é } \\
\text { observado }\end{array}$} & \multicolumn{3}{|c|}{$\begin{array}{l}\text { Aulas em } \\
\text { que PP é } \\
\text { observado }\end{array}$} \\
\hline & & 1 & 2 & 3 & 1 & 2 & 3 \\
\hline \multirow{3}{*}{$\mathrm{I}$} & I.1. comportamentos do professor & $\mathrm{x}$ & $\mathrm{x}$ & $\mathrm{x}$ & $\mathrm{x}$ & $\mathrm{x}$ & $\mathrm{x}$ \\
\hline & I.2. comportamentos dos alunos & $\mathrm{x}$ & $\mathrm{x}$ & $\mathrm{x}$ & $\mathrm{x}$ & $\mathrm{x}$ & $\mathrm{x}$ \\
\hline & I.3. condução do processo de ensino pelo professor & $\mathrm{x}$ & $\mathrm{x}$ & $\mathrm{x}$ & $\mathrm{x}$ & $\mathrm{x}$ & $\mathrm{x}$ \\
\hline \multirow{4}{*}{$\begin{array}{c}\text { Descrição } \\
\text { de } \\
\text { Ocorrências }\end{array}$} & I.4. participação/intervenção dos alunos & $\mathrm{x}$ & $\mathrm{x}$ & $\mathrm{x}$ & $\mathrm{x}$ & $\mathrm{x}$ & $\mathrm{x}$ \\
\hline & I.5. iniciativa/autonomia dos alunos & $\mathrm{x}$ & $\mathrm{x}$ & & $\mathrm{x}$ & $\mathrm{x}$ & \\
\hline & I.6. interações entre professor e aluno(s) & $\mathrm{x}$ & $\mathrm{x}$ & & $\mathrm{x}$ & $\mathrm{x}$ & $\mathrm{x}$ \\
\hline & I.7. interações entre alunos & $\mathrm{x}$ & $\mathrm{x}$ & & & $\mathrm{x}$ & \\
\hline \multirow{6}{*}{$\begin{array}{c}\text { Interpretações } \\
\text { do } \\
\text { Observador }\end{array}$} & II.1. sobre a gestão do tempo & $\mathrm{x}$ & $\mathrm{x}$ & & & $\mathrm{x}$ & \\
\hline & II.2. sobre a atitude de aprendizagem & $\mathrm{x}$ & $\mathrm{x}$ & $\mathrm{x}$ & $\mathrm{x}$ & $\mathrm{x}$ & $\mathrm{x}$ \\
\hline & II.3. sobre a gestão de conflitos/comportamentos & $\mathrm{x}$ & $\mathrm{x}$ & $\mathrm{x}$ & $\mathrm{x}$ & $\mathrm{x}$ & $\mathrm{x}$ \\
\hline & II.4. sobre a gestão de recursos e materiais & & $\mathrm{x}$ & $\mathrm{x}$ & & $\mathrm{x}$ & \\
\hline & II.5. sobre a gestão da comunicação & $\mathrm{x}$ & $\mathrm{x}$ & & $\mathrm{x}$ & & $\mathrm{x}$ \\
\hline & II.6. sobre a gestão das atividades/estratégias & $\mathrm{x}$ & $\mathrm{x}$ & $\mathrm{x}$ & $\mathrm{x}$ & $\mathrm{x}$ & $\mathrm{x}$ \\
\hline \multirow{4}{*}{$\begin{array}{c}\text { III } \\
\text { Questionamento } \\
\text { da parte do } \\
\text { Observador }\end{array}$} & III.1. concordância entre observador e observado & $\mathrm{x}$ & $\mathrm{x}$ & & & $\mathrm{x}$ & $\mathrm{x}$ \\
\hline & III.2. discordância entre observador e observado & $\mathrm{x}$ & $\mathrm{x}$ & $\mathrm{x}$ & & $\mathrm{x}$ & \\
\hline & III.3. justificação por parte do observado & $\mathrm{x}$ & $\mathrm{x}$ & $\mathrm{x}$ & $\mathrm{x}$ & $\mathrm{x}$ & $\mathrm{x}$ \\
\hline & III.4. incompreensão da parte do observador & $\mathrm{x}$ & $\mathrm{x}$ & $\mathrm{x}$ & $\mathrm{x}$ & & $\mathrm{x}$ \\
\hline \multirow{5}{*}{$\begin{array}{l}\text { Feedback do } \\
\text { Observado }\end{array}$} & IV.1. reflexão sobre a observação mútua de aulas & $\mathrm{x}$ & & $\mathrm{x}$ & & $\mathrm{x}$ & \\
\hline & IV.2. reflexão sobre os dados da observação & $\mathrm{x}$ & $\mathrm{x}$ & $\mathrm{x}$ & $\mathrm{x}$ & $\mathrm{x}$ & $\mathrm{x}$ \\
\hline & $\begin{array}{l}\text { IV.3. mudança ao nível das perceções / conceções em } \\
\text { resultado da observação de aulas }\end{array}$ & & & & & $\mathrm{X}$ & \\
\hline & $\begin{array}{l}\text { IV.4. mudança ao nível das opções para a condução do } \\
\text { processo de ensino, em resultado da observação } \\
\text { de aulas }\end{array}$ & & $\mathrm{X}$ & & & $\mathrm{X}$ & \\
\hline & $\begin{array}{l}\text { IV.5. mudança ao nível das ocorrências, em resultado } \\
\text { da observação de aulas }\end{array}$ & & $\mathrm{X}$ & & & & $\mathrm{X}$ \\
\hline
\end{tabular}

Fonte: Elaborada pelos autores. 
A terceira categoria, "Questionamento da parte do Observador", centrou-se tanto nos comentários e inferências do observador como no feedback do observado, tendo produzido quatro constantes, ou subcategorias. Registe-se que a única subcategoria que ocorre em todas as grelhas de observação é a III.3 (“justificação por parte do observado"). No entanto, em cinco das seis grelhas de observação, encontram-se registos que indiciam incompreensão por parte do observador, perante situações ocorridas, e que demonstram a interação reflexiva entre observador e observado, como é exemplo:

[...] do ponto de vista de observador tem-se a sensação de que "muita aula" vai-se perdendo por trás do grupo, e que é difícil ter uma percepção da aprendizagem de cada aluno, até porque provavelmente acaba sempre por haver um porta-voz e os outros resignam-se a aceitar o que é dito pelo porta-voz.

A quarta categoria, "Feedback do Observado", permitiu encontrar cinco constantes, ou subcategorias: duas que dizem respeito à reflexão (sobre a observação mútua de aulas e sobre os dados recolhidos através da observação da aula) e três que dizem respeito às mudanças operadas nos indivíduos e na sua ação, em resultado da observação mútua das aulas (ao nível das percepções e concepções, ao nível das opções tomadas na condução do processo de ensino e ao nível das ocorrências nas aulas.

A análise das 19 reflexões escritas individualmente por PI permite constatar que a "insegurança" é uma constante nas primeiras onze reflexões. De igual forma, referências explícitas ao "Estado de Alma: Confiança" aparecem em quatro reflexões. A motivação, outro dos "Estados de Alma", aparece referida em cinco reflexões.

O sentimento de que o projeto/estudo contribuiu para a transformação pessoal é referido ao longo da reflexão final, onde é referido que "ajudou-nos [...] a destruir preconceitos sobre sermos observados em ação na sala de aulas" e que "serve de estímulo para preparar melhor as aulas, para diversificar as estratégias e as atividades".

No caso de PP, confrontadas as reflexões inicial e final, constata-se uma evolução: a primeira é curta e dá conta do seu desconhecimento acerca daquilo que é o trabalho colaborativo entre professores e das suas baixas expetativas quanto à sua participação no projeto/estudo, particularmente dada a insegurança inicial; na última, ainda que se encontrem indícios de insegurança, PP manifesta-se motivada e é capaz de identificar transformações em si própria: “Ora, a possibilidade deste trabalho 
colaborativo abriu então uma janela que há muito estava fechada: os alunos podem-nos surpreender, mas os professores também podem surpreender os alunos".

As transcrições das sessões com os grupos focalizados de alunos foram analisadas, sendo encontradas quatro categorias: na primeira, os alunos refletem sobre a própria aprendizagem; na segunda, os alunos refletem sobre o grupo-turma; na terceira, os alunos refletem sobre o currículo e a relevância dos conteúdos; na quarta e última, os alunos refletem sobre o seu professor (Tabela 4).Pode, desde logo, inferir-se que os alunos, quando orientados, podem atingir o mesmo nível de reflexão que os professores e contribuir para um melhor conhecimento e uma melhor compreensão dos processos que se estabelecem na relação pedagógica.

A leitura e análise das reflexões individuais dos alunos, escritas no final da sua participação neste estudo, permitiu encontrar quatro categorias: a primeira, "Mudanças ao nível do ensino-aprendizagem”, agrupa as referências que indiciam mudanças associadas a este estudo. De notar que foram encontrados os seguintes grupos de referências, que constituem as seis subcategorias:

1. mudanças no professor, ao nível das metodologias de ensino (13 referências);

2. mudanças na motivação dos alunos em resultado da alteração das metodologias de ensino (10 referências);

3. essas mudanças ao nível da motivação derivam ainda da percepção dos alunos de que as aulas são mais interativas, há mais recurso ao trabalho colaborativo entre alunos e às tecnologias (8 referências);

4. em menor número, refletem sobre a eficácia das opções tomadas (2);

5. incentivam o professor a continuar na mudança/inovação (1); e

6. referem que o professor não dá apoio personalizado (1).

A segunda categoria, "Mudanças ao nível dos hábitos reflexivos", agrupa as referências que indiciam reflexão sobre o processo de ensino e aprendizagem:

1. referências associando a motivação dos alunos à qualidade da sua aprendizagem(5 referências); e

2. referências a reflexões sobre a própria aprendizagem (3). 
Tabela 4 - Grelha de codificação das transcrições das sessões com os grupos focalizados

\begin{tabular}{|c|c|c|}
\hline CATEGORIAS & SUBCATEGORIAS & $\begin{array}{c}\text { FREQUÊN- } \\
\text { CIA }\end{array}$ \\
\hline & I.1. Indiciam consciência auto avaliativa & 18 \\
\hline I - REFLETEM & I.2. Indiciam consciência sobre a motivação para a aprendizagem & 35 \\
\hline SOBRE A & I.3. Identificam pontos fracos & 15 \\
\hline PRÓPRIA & I.4. Identificam pontos fortes & 7 \\
\hline \multirow[t]{4}{*}{ APRENDIZAGEM } & I.5. Manifestam consciência dos processos mentais & 22 \\
\hline & $\begin{array}{l}\text { I.6. Manifestam consciência dos processos de organização e } \\
\text { método de estudo }\end{array}$ & 7 \\
\hline & $\begin{array}{l}\text { I.7. Manifestam consciência das especificidades da aprendizagem } \\
\text { das línguas }\end{array}$ & 11 \\
\hline & $\begin{array}{l}\text { I.8. Refletem sobre inter-relações entre avaliação e processo } \\
\text { ensino-aprendizagem }\end{array}$ & 22 \\
\hline II - REFLETEM & II.1. Refletem sobre as inter-relações que se estabelecem no grupo & 24 \\
\hline $\begin{array}{l}\text { SOBRE O } \\
\text { PROCESSO DE }\end{array}$ & $\begin{array}{l}\text { II.2. Refletem sobre as inter-relações que se estabelecem com o } \\
\text { professor }\end{array}$ & 31 \\
\hline \multirow[t]{2}{*}{$\begin{array}{l}\text { ENSINO E O } \\
\text { GRUPO- TURMA }\end{array}$} & $\begin{array}{l}\text { II.3. Refletem sobre a forma como o processo de ensino e } \\
\text { aprendizagem é conduzido }\end{array}$ & 48 \\
\hline & $\begin{array}{l}\text { II.4. Refletem sobre a eficácia das opções tomadas ao nível do } \\
\text { processo de ensino }\end{array}$ & 50 \\
\hline III - REFLETEM & $\begin{array}{l}\text { III.1. Indiciam consciência de um projeto pessoal de } \\
\text { desenvolvimento }\end{array}$ & 18 \\
\hline $\begin{array}{l}\text { SOBRE O } \\
\text { CURRÍCULO E }\end{array}$ & $\begin{array}{l}\text { III.2. Valorizam a língua inglesa enquanto instrumento de } \\
\text { comunicação }\end{array}$ & 35 \\
\hline A RELEVÂNCIA & III.3. Valorizam a língua inglesa enquanto disciplina & 15 \\
\hline \multirow[t]{2}{*}{$\begin{array}{l}\text { DOS } \\
\text { CONTEÚDOS }\end{array}$} & $\begin{array}{l}\text { III.4. Manifestam consciência crítica sobre a metodologia e os } \\
\text { objetivos envolvidos }\end{array}$ & 20 \\
\hline & IV.1. Identificam mudanças ao nível do processo de ensino & 5 \\
\hline IV - REFLETEM & IV.2. Identificam mudanças ao nível da comunicação & 1 \\
\hline SOBRE O & IV.3. Identificam mudanças ao nível da avaliação & 1 \\
\hline PROFESSOR & IV.4. Refletem sobre o papel do professor & 13 \\
\hline
\end{tabular}

Fonte: Elaborada pelos autores. 
A terceira categoria, "Mudanças ao nível afetivo", agrupa um conjunto de referências que associam as questões da comunicação/afetividade e a motivação e qualidade da aprendizagem dos alunos:

1. sete alunos referem que a boa relação afetiva entre professor e aluno(s) melhora a motivação destes;

2. um aluno refere que o diálogo contribui para aprofundar a afetividade e 1 aluno refere que o diálogo contribui para melhor compreender os papéis de cada um (professor e alunos); e

3. um aluno refere a capacidade do professor em ouvir e dar liberdade de expressão aos seus alunos.

A quarta categoria, "Mudanças ao nível da avaliação" agrupa algumas referências a alterações no professor ao nível do processo de avaliação dos seus alunos:

1. três alunos referem que o professor é justo na avaliação (heteroavaliação); e

2. um aluno valoriza língua Inglesa como uma vantagem para o seu futuro (autoavaliação).

A leitura e análise das transcrições das sessões com os grupos focalizados e das reflexões individuais dos alunos permitiu identificar suas percepções acerca das transformações que se operam ao nível do desempenho pessoal e profissional do seu professor, envolvido num processo de supervisão pedagógica interpares (Tabela 5). Constata-se que identificam um conjunto de transformações nos seus professores, em conformidade com aquilo que era pretendido: por um lado, a forma como os alunos concebem o processo de ensino e aprendizagem e, por outro, a forma como eles interpretam o processo de ensino e aprendizagem à luz da sua própria experiência.

Tabela 5 - Síntese das perceções dos alunos acerca dos seus professores e da sua ação

Perceções dos alunos:

1. Os alunos identificam mudanças ao nível metodológico, as quais derivam da capacidade do professor em selecionar recursos e estratégias e de tomar decisões.
Transcrições ilustrativas (Reflexões Individuais dos Alunos do $9^{\circ}$ ano):

"Neste ano entrei para a sala para ter Inglês a pensar que iria ser como todos os anos, mas enganei-me. As aulas de Inglês estão mais divertidas."

"Em relação ao ano passado, as suas aulas eram muito pesadas e muito teóricas. Talvez necessitassem de mais dinâmica como este ano."

"Comparando com anos anteriores, eu penso que as aulas estão muito diferentes e mudaram para melhor."

"Na minha opinião, o professor tem tido algumas mudanças durante os anos."

"Na minha opinião, as aulas têm vindo a evoluir satisfatoriamente." 
2. Alguns alunos têm a perceção de que as transformações podem ser continuadas ou reversíveis, não se tratando de um processo inequívoco nem irreversível.
"Acho que o stôr deve continuar assim e evoluir para melhor e não voltar ao passado."
3. Os alunos têm a perceção de que os contextos de aprendizagem caraterizados pela interatividade são mais motivadores.
"As aulas de Inglês são muito interativas, é muito agradável aprender, vendo filmes e ouvindo música."

"Eu acho que as aulas de Inglês são muito interativas e divertidas. Os alunos revelam-se mais atentos e interessados através destes métodos."
4. Alguns alunos referem a relação entre motivação e aprendizagem.

5. Alguns alunos relacionam motivação com afetividade na relação pedagógica.
"Houve uma altura em que as aulas se tornaram um bocado diferentes, o que levou a que a minha vontade de ter Inglês diminuísse, mas passado algum tempo tudo voltou a melhorar e agora gosto de ter Inglês e sinto-me motivado, sei que o inglês é uma língua de que vou precisar no futuro."

"Dialogar com os alunos é muito importante, faz-nos sentir à vontade para aprendermos mais e melhor." (Aluno 6)

"Quanto ao professor, acho que tem conseguido impor mais disciplina mas tem ouvido mais as nossas opiniões e dúvidas. Em questão de aula, consegue falar de tudo o que está estipulado no sumário e ainda proporciona momentos de diálogo e descontração."

Fonte: Elaborada pelos autores.

Os dados confirmam transformações nos professores ao nível da forma como planificaram, desenvolveram e avaliaram o processo de ensino e aprendizagem em contexto de sala de aula, dando uma resposta positiva à primeira questão do estudo. Estas transformações resultam da reformulação constante da abordagem metodológica em consequência das práticas reflexivas e da observação mútua de aulas e confirmam a ideia defendida por Oliveira, Melo e Moreira (2005) de que a observação interpares com recurso aos textos reflexivos é uma importante estratégia de transformação da pedagogia, pois desencadeia o diálogo entre pares e promove a elaboração e reconstrução das suas teorias e práticas. Confirma-se também que a escrita reflexiva é um espaço de partilha de situações, problemas ou dilemas, necessária à transformação das práticas pedagógicas.

A transformação dos professores foi referida pelos seus alunos durante as sessões com os grupos focalizados de alunos, identificando com maior frequência mudanças ao nível do processo de ensino e, com menor frequência, mudanças ao nível da comunicação e ao nível da avaliação. Também nas reflexões escritas dos alunos se 
encontram referências a mudanças: ao nível das metodologias de ensino, ao nível dos contextos de aprendizagem e ao nível das estratégias e dos recursos utilizados.

Foram ainda identificadas transformações nos professores ao nível das práticas reflexivas e dos conteúdos das mesmas, seja sob a forma de autorreflexão, seja sob a forma de reflexão colaborativa entre professores e entre estes e os seus alunos, o que permite dar uma resposta positiva à segunda questão deste estudo. A análise dos dados demonstra que a reflexão colaborativa é um fator de mudança, os ciclos de observação de aulas despoletam a reflexão colaborativa e a mudança entre os professores e, consequentemente, o estudo constituiu um instrumento de desenvolvimento profissional e pessoal. Os ganhos pessoais são assinaláveis, pois ambos os participantes reconheceram que:

$\checkmark$ Mudaram a sua perspetiva pessoal acerca dos alunos e dos contextos de ensino e aprendizagem em resultado de ouvirem os relatos, as opiniões, as perceções e as reflexões do/a colega;

$\checkmark$ Ganharam um estímulo adicional para inovarem e diversificarem estratégias ao nível do processo de ensino e aprendizagem;

$\checkmark$ Renovaram o gosto e o prazer de dar aulas;

$\checkmark$ O estudo implicou procura de informação e renovação profissional, que deu uma nova perspetiva à formação e ao desenvolvimento profissional;

$\checkmark$ A reflexão dialógica permitiu constatar a existência de uma clivagem entre intenções e prática (DAY, 2001), mas que ao longo do processo deixou de ser um problema para se tornar numa oportunidade de mudança;

$\checkmark \mathrm{O}$ estudo contribuiu para a mudança da sua perspetiva do processo de ensino, passando de uma perspetiva restrita para uma perspetiva alargada (do domínio do professor, para o domínio dos contextos);

$\checkmark \mathrm{O}$ estudo fez compreender a natureza e as virtualidades do trabalho colaborativo, aprofundando a confiança entre colegas e a sensação de que a colaboração não tem nada a ver com violação de domínios pessoais de ação;

$\checkmark$ Existiu uma mudança assinalável tanto ao nível da forma como do conteúdo da reflexão dialógica: se inicialmente o diálogo se centrava nos problemas e na desculpabilização pessoal de cada professor, centrando o foco na desmotivação e na falta de participação e motivação dos alunos, progressivamente foi sendo centrada no papel do professor e na qualidade das suas decisões.

As mudanças identificadas nos alunos, ao nível do conhecimento e da consciência acerca do papel do professor, permitem dar uma resposta positiva à terceira questão deste estudo. Estas mudanças evidenciam que os alunos conseguem elaborar um quadro global do desempenho do seu professor, estruturado sobre um conjunto de conhecimentos, crenças e valores e permitem concluir que os alunos têm uma perspetiva positiva da influência que os professores exercem sobre o clima educativo. Reflexões 
como "dialogar com os alunos é muito importante, faz-nos sentir à vontade para aprendermos mais e melhor" permitem concluir que os alunos têm consciência de que a comunicação entre professor e aluno/alunos constitui um fator positivo na sua aprendizagem, realçando as questões da afetividade e a sua ação sobre a motivação. Um dos aspetos que aparece mais marcadamente referido pelos alunos quando falam do diálogo e da inter-relação entre professor e aluno, é a capacidade deste saber ouvir e dar aos alunos a oportunidade e a possibilidade de exprimirem as suas ideias e opiniões, pois a interação e a troca de ideias permitem que os alunos concluam: "Acho que nós pensamos com a nossa própria cabeça”.

Os dados permitem também concluir que podem ser identificadas mudanças ao nível das aprendizagens dos alunos em consequência das transformações operadas ao nível do desempenho profissional e pessoal dos professores, dando uma resposta positiva à quarta questão deste estudo. $\mathrm{O}$ trabalho colaborativo, a observação e a reflexão mútuas tiveram um impacto transformacional, pois induziram os professores participantes a modificar as suas práticas de ensino e a forma de comunicar/dialogar com os alunos, incrementando nestes a motivação e a compreensão do processo de ensino e aprendizagem:

$\checkmark$ A procura do feedback dos alunos levou a uma maior aproximação entre alunos e professores, melhorando, portanto, a relação pedagógica.

$\checkmark$ Os alunos demonstraram mais motivação para as aulas, com a diversidade de materiais e estratégias utilizados pelos professores e com o facto de terem sentido que o professor se preocupava com as suas opiniões e dificuldades.

$\checkmark$ O reconhecimento explícito da dedicação dos professores, por parte dos alunos, reforçou a motivação daqueles, tornando-se evidente que é possível resolver os problemas emergentes no contexto da sala de aulas.

\section{Conclusões}

Este estudo pode ser visto simultaneamente como um processo de autoscopia e heteroscopia, pois recorreu a estratégias de autorreflexão e reflexão colaborativa, tendo como finalidade exercer influência sobre o próprio e o outro. Os resultados estão em consonância com outros desenvolvidos por Moreira et al., (2010), na medida em que se demonstra que o recurso à investigação-ação num contexto de supervisão interpares, enquanto instrumento de desenvolvimento pessoal e profissional do professor, é uma estratégia de renovação da ação educativa, ao permitir a reflexão crítica sobre a ação profissional, em colaboração estreita com outros atores educativos. De facto, verifica-se 
que é um modelo em que os professores estudam a aprendizagem dos alunos relacionando-a com o seu próprio ensino, processo pelo qual aprendem sobre as suas próprias práticas e introduzem inovações e mudanças com vista a melhorar as aprendizagens dos alunos.

A participação dos alunos num processo de Supervisão Pedagógica Interpares em contexto de Desenvolvimento Pessoal e Profissional de professores é estratégica, na medida em que permite a recolha de dados relativos às opiniões e percepções daqueles a quem se destina o processo de ensino e a posterior triangulação com os dados resultantes de outras fontes. Para além disso, a reflexão colaborativa entre o professor e os seus alunos acarreta vantagens acrescidas para o processo reflexivo entre professores, na medida em que permite conhecer o impacto das decisões no processo de ensino e identificar os interesses e as necessidades no processo de aprendizagem.

\title{
PEER EDUCATIONAL SUPERVISION AIMING PERSONAL AND PROFESSIONAL DEVELOPMENT OF TEACHERS: AN EXPLORATORY STUDY
}

\begin{abstract}
This article presents a study which included a process of Peer Pedagogical Supervision as a way to contribute to Personal and Professional Development of the teachers involved and to improve the quality of learning of their students. It was a process of action research, using cycles of mutual observation of classes by the participating teachers, and the consequent collaborative reflection. Theories that support the pedagogical action in interactive, ecological and developmental perspectives were tested - in which the teaching is not unique to the teacher nor the learning is unique to the student. It is rather a transformation process which seeks autonomy for teachers and students through reflection, the systematic acquisition of new knowledge, innovation (experimentation and evaluation of new methods, resources and forms of communication), for purposes of educational innovation, school improvement and transformation of society.
\end{abstract}

KEYWORDS: Pedagogical supervision. Peer pedagogical supervision. Teacher collaboration. Action-research. Personal and professional development of teachers.

\section{REFERÊNCIAS}

ALARCÃO, I. Prefácio. In: ANDRADE, A. I.; PINHO, A. S. Línguas e educação:

práticas e percursos de trabalho colaborativo. Perspetivas a partir de um projeto. Aveiro: Universidade de Aveiro, 2010a. p.7-10.

Supervisão: um contexto de desenvolvimento profissional dos professores.

2.ed. Mangualde: Edições Pedago, $2010 \mathrm{~b}$. 
BINDÉ, J. et al. Rumo às sociedades do conhecimento: relatório mundial da UNESCO. Lisboa: Instituto Piaget, 2007.

COUTINHO, C. et al. Investigação-acção: metodologia preferencial nas práticas educativas. Revista Psicologia, Educação e Cultura, Braga, v.13, n.2, p.455-479, 2009.

DAY, C. A passion for teaching. London: Routledge Falmer, 2004.

Desenvolvimento profissional de professores: os desafios da aprendizagem permanente. Porto: Porto Editora, 2001.

Developing teachers: the challenges of lifelong learning. New York:

Routeledge Falmer, 1999.

et al. Teachers matter: connecting lives, work and effectiveness. Berkshire:

Open University Press, 2007.

GLICKMAN, C. et al. Supervision and instructional leadership. 8.ed. Boston: Pearson, 2010.

MOREIRA, M. A. A investigação-ação na formação reflexiva do professorestagiário de inglês. Lisboa: Instituto de Inovação educacional, 2001.

. A supervisão pedagógica como espaço de transformação pessoal e profissional na educação em línguas estrangeiras. In: BIZARRO, R. M. Supervisão pedagógica e educação em línguas. Mangualde: Edições Pedago, 2010. p.91-110.

. et al. A investigação-ação na formação reflexiva de professores em formação inicial: percursos e evidências de um projeto de supervisão. In: VIEIRA, F. No caleidescópio da supervisão: imagens da formação e da pedagogia. Mangualde: Edições Pedago, 2010. p.47-80.

OLIVEIRA, L.; MELO, M.; MOREIRA, M. Observação interpares: análise de uma prática colaborativa. In: VIII CONGRESSO GALAICO-PORTUGUÊS DE PSICOPEDAGOGIA, 2005, Braga. Actas do VIII Congreso Galaico-Portugués de Psicopedagoxía, 2005. p.2885.

SCHÖN, D. Educando o profissional reflexivo. Um novo design para o ensino e a aprendizagem. Porto Alegre: ARTMED, 2000.

VIEIRA, F. Para uma visão transformadora da supervisão pedagógica. Educação \& Sociedade, Campinas, v.29, n.105, p.197-217, jan./abr. 2009.

; MOREIRA, M. Supervisão e avaliação do desempenho docente: para uma abordagem de orientação transformadora. Lisboa: Cadernos do CCAP-1. Ministério da Educação, 2011.

ZEPEDA, S. Instructional supervision: applying tools and concepts. 2.ed. New York: Eye On Education, 2007.

Professional development: what works. New York: Eye On Education, 2008. 